\title{
PHYTOCHEMICAL AND QUALITATIVE CHARACTERIZATION OF LEAVES OF SOME NOTEWORTHY MEDICINAL PLANTS OF CHHATTISGARH, INDIA
}

\author{
Reena V. Mathai ${ }^{1, \bowtie}$, Jayati Chatterjee Mitra ${ }^{1}$ and Santosh Kumar Sar ${ }^{2}$ \\ ${ }^{1}$ Department of Chemistry, Dr C.V. Raman University, Kota, Bilaspur-495113, \\ Chhattisgarh, India. \\ ${ }^{2}$ Department of Applied Chemistry, Bhilai Institute of Technology, Durg-490001, \\ Chhattisgarh, India. \\ ${ }^{\square}$ Corresponding Author: jasmathai@gmail.com
}

\begin{abstract}
The diverse pharmacological properties of medicinal plants are due to the presence of certain biologically active chemical compounds known as Phytochemicals. The present analysis was carried out to characterize the phytochemicals present in the leaves of five selected noteworthy medicinal plants. Leaf extracts of Clitoria ternatea, Calotropis gigantea, Mentha Arvensis, Aegle marmelos and Catharanthus roseus were made by using three solvents methanol, ethanol and chloroform and these extracts have been evaluated using Ultra Violet Visible (UV-VIS) and Fourier-Transform Infrared (FTIR) spectrophotometer. The results of FTIR and UV-VIS spectral values and the qualitative phytochemical screening done by standard methods confirm the presence of certain phytochemicals such as terpenoids, flavonoids, glycosides, carbohydrates, quinones, tannins, saponins, alkaloids, steroids, and phenols in the selected plant leaves. Methanol extracts of the plant leaves were found to consist of a good source of phytochemicals as compared to the chloroform and ethanol extract. The present study validates that selected plant leaves are an excellent source of significant phytochemicals and can be used in the production of herbal formulation, useful drugs and alternative medicines.
\end{abstract}

Keywords: Alkaloids, Bioactive Compound, FTIR and UV-VIS, Medicinal Plant, Phytochemicals

RASĀYAN J. Chem., Vol. 14, No.2, 2021

\section{INTRODUCTION}

Medicinal plants are used from the beginning of human history, to promote a healthy life for humans and animals. The bio-resource of various components used in conventional medicines, food supplements, pharmaceutical products, and natural products are widely provided by medicinal plants. As per WHO estimation, $80 \%$ of the world's population consumes herbs for various aspects in health, disease control and healing measures. ${ }^{1}$

The medicinal properties of the plant can be attributed to the formation of certain phytochemicals or biologically active components in the plant which are responsible for various physiological effects on the human body. ${ }^{2}$ The biologically active chemical compounds found naturally in plants are known as phytochemicals which protect the plant from environmental hazards and attack of pathogens. These chemicals are often referred to as 'secondary metabolites' and give health benefits to human beings. ${ }^{3}$ The nutrients are consumed more effectively for the various metabolisms in the body due to these secondary metabolites and hence they are considered synergistic agents. The phytochemicals such as flavonoids, steroids, alkaloids, phenolic compounds, tannins, and lignin's play a vital role against various diseases and do not have any side effects on human beings and known as "human-friendly medicines". ${ }^{4}$ Due to the diverse pharmacological properties of phytochemicals like antimicrobial, antioxidant, anticancer, modulation of hormone metabolism and antineoplastic properties, it has received considerable attention in recent year. ${ }^{5}$ These phytochemicals can be used as potential medicinal agents due to their negligible toxicity, low cost and easy availability. ${ }^{6}$ The medicinal plant which contains these phytochemicals in one or more of its organs can be used for the therapeutic purpose or that are precursors for the synthesis of 
RASĀYAN J. Chem.

Vol. 14 | No. 2 |1423-1434| April - June | 2021

useful drugs. ${ }^{7}$ Literature reviews report that medicinal plants bioactive chemical constituents greatly vary with the genetic factor, climatic changes, soil and other factors. ${ }^{8}$

In the present study, it has been tried to characterize the various functional groups of phytochemical compounds in the extracts made from leaves of the selected five Indian medicinal plants. Clitoria ternatea belonging to the Fabaceae family is a traditional herb with maximum therapeutic properties. It is a common plant found in India and is commonly known as "butterfly pea". It is a perennial plant, with elliptic, obtuse leaves. It grows as a vine or creeper, well in moist and neutral soil. ${ }^{9}$ For centuries it has been applied as a constituent of medicine in Ayurveda, generally used as an anticonvulsant, memory enhancer, antidepressant, anxiolytic, antistress, nootropic, tranquillizing and sedative agent for treating various ailments. ${ }^{10}$ Calotropis gigantea belonging to family Asclepiadaceae is known as "Sweta Arka"11 or milkweed is scientifically reported for antidiarrheal activity, anti-Candida activity, antibacterial activity and antioxidant activity. ${ }^{12}$ Mentha arvensis Linn, a species of mint belonging to the family Lamiaceae is a commonly found aromatic edible herb throughout India. It has wide applications in industries such as cosmetic, pharmaceutical and flavouring..$^{13}$ Mentha shows antioxidant properties as it consists of bioactive compounds like menthone, menthol, flavonoids, rosmarinic acid and carvone. ${ }^{14}$ Aegle marmelos (Rutaceae family) are commonly known as Bael. The parts of this plant are used for medicinal purposes. The leaves are used as a mild laxative, in cure of wound, leucorrhoea, deafness and as an antiinflammatory agent. ${ }^{15}$ Catharanthus roseus is native to Madagascar (Family Apocynaceae) is commonly called Madagascar periwinkle. It is a perennial evergreen herb that has many types of terpenoids, alkaloids used in the cure of lymphocytic cancer, Wilkins's cancer, neuroblastoma and reticulum cell tumour and Hodgkin's disease. ${ }^{16}$

For the establishment of new drugs, it is important to evaluate the medicinal composition and properties of these bioactive compounds in plants. Spectroscopic methods such as FTIR and UV-VIS are very rapid and cost-effective. UV-VIS spectroscopy reveals the photons activity in the UV-VIS region. The colour of the molecule affects the absorption spectra. Molecules that undergo electronic transitions and spectra can be used to compute polynuclear compounds, functional group present and extent of conjugation by comparing with the standard. ${ }^{17}$ Fourier Transform Infrared spectroscopy (FTIR) is an analytical technique that has high resolution and provides structural and functional properties of Phyto-compounds. The chemical bonds present in a molecule can be identified by elucidating the infrared spectrum. Each chemical bond has a characteristic wavelength that can be seen in the spectrum..$^{18}$ It is based on absorption frequencies which are formed by the vibration of bonds in the functional groups and give a spectrum that can be considered as a 'fingerprint' to differentiate and define the functional groups in respective bioactive compounds. In the present study phytochemical characterization of the five selected medicinal plants was done by standard methods, UV-VIS and FTIR to identify these secondary metabolites or the bioactive compounds present which can be used as a natural blueprint for the generation of the new drug.

\section{Collection of Samples}

\section{EXPERIMENTAL}

Fresh leaves of five selected plants from the Bhilai region (Chhattisgarh, India) were collected in the month of May-June. The leaves were cleaned with tap water and distilled water. The leaves were dried first in shade and then in an air oven. The dried leaves were then crushed and ground into a powder with a mechanical grinder, sieved and particle size of $100 \mu \mathrm{m}$ was stored in an airtight container and used for further investigation.

\section{Chemicals}

Analytical grade reagents were utilized in this work. Hydrochloric acid and sulphuric acid were obtained from Loba Chemie Pvt. Ltd. India. Solvents such as methanol, ethanol and chloroform from Merck, India were used.

\section{Preparation of Plant Extract}

The extracts of selected sample powder were prepared by soaking $10 \mathrm{~g}$ of dried powder in $100 \mathrm{ml}$ methanol, ethanol and chloroform solvent separately and rotated in a rotary shaker at $100 \mathrm{rpm}$ for $72 \mathrm{~h}$ at 
RASĀYAN J. Chem.

Vol. 14 | No. 2 |1423-1434| April - June | 2021

room temperature. The extracts were filtered by using filter paper (Whatman No.41) separately and kept in the refrigerator at $4^{\circ}-7^{\circ} \mathrm{C}$. The filtered extracts of the selected plant leaf samples were used for further analysis of phytochemicals.

\section{Phytochemicals Screening of Samples}

The methanol, ethanol and chloroform extracts of the selected plants were subjected to phytochemical screening and bioactive compounds were determined by using the standard methods. ${ }^{2,4,19 \text {, and } 20}$

\section{Detection of Alkaloids: Mayer's Test}

Dilute Hydrochloric acid is used to dissolve plant extracts prepared separately and then filtered. To $2 \mathrm{ml}$ of Potassium Mercuric Iodide (Mayer's reagent) add a few $\mathrm{ml}$ of filtrate. The presence of alkaloids is indicated by a yellow precipitate observed.

\section{Detection of Carbohydrates: Molisch's Test}

The leaf extracts were dissolved separately in $5 \mathrm{ml}$ distilled water and then filtered. In a test tube, to the above filtrates added alcoholic $\alpha$-naphthol (1-2 drop). The violet ring formed at the junction confirms the Carbohydrates present.

\section{Detection of Glycosides: Modified Borntrager's Test}

Plant leaf extracts were treated first with dilute hydrochloric acid and are used to test for glycosides. The above extracts were mixed with $\mathrm{FeCl}_{3}$ solution and kept over boiling water for 5-7 minutes. It is allowed to cool and then an equal volume of benzene is added. The layer of benzene separates out and then it is combined with a solution of ammonia. The presence of glycosides is confirmed by the pink colour formed in the layer of ammonia.

\section{Detection of Saponins: Foam Test:}

$1 \mathrm{gm}$. of extract and $4 \mathrm{ml}$ of water is shaken properly. The foam produced and lasted for ten to fifteen minutes thus it infers saponins.

\section{Detection of Phenols: Ferric Chloride Test}

Extracts of leaves were mixed with 4-5 drops of a solution of $\mathrm{FeCl}_{3}$. The bluish-black colour formed indicates the presence of phenol.

\section{Detection of Tannins: Gelatin Test}

Gelatin solution (1\%) containing sodium chloride is added to each leaf extract. The white precipitate formed infers that tannins are present.

\section{Detection of Flavonoids: Lead acetate Test}

4-5 drops of lead acetate solution are added to the plant extract. The presence of flavonoids is revealed by the yellow precipitate formed.

\section{Detection of Quinones}

Add concentrated hydrochloric acid to a few $\mathrm{ml}$ of extract. The yellow-coloured precipitate produced reveals the quinones present in the extract.

\section{Detection of Terpenoids: Liebermann-Burchard Test}

To $1 \mathrm{ml}$ of plant extract added a few $\mathrm{ml}$ of chloroform, acetic anhydride and 2-3 drops of $\mathrm{H}_{2} \mathrm{SO}_{4}$ and if dark green colour is formed then it confirms terpenoids.

\section{Detection of Steroids}

To the plant, extract add $3 \mathrm{ml}$ of chloroform and sulphuric acid and mix them properly. The presence of steroids is indicated by the red colour produced after few minutes in the lower layer of chloroform. 
RASĀYAN J. Chem.

Vol. 14 | No. 2 |1423-1434| April - June | 2021

\section{Spectroscopic Analysis by UV-VIS Spectra}

The selected plant leaf extracts were scanned under visible and Ultraviolet light by using a UV -VIS spectrophotometer (117- Systronics, Baden, Switzerland) matched with a $1 \mathrm{~cm}$ quartz cell at room temperature. The wavelength range selected for scanning was $200-700 \mathrm{~nm}$. The peaks observed were differentiated and recorded the wavelength values of the peaks.

\section{Spectroscopic Analysis by FTIR}

For FTIR analysis, $10 \mathrm{mg}$ of the dried leaf extract powder was encapsulated in $100 \mathrm{mg}$ of $\mathrm{KBr}$ pellet, to prepare translucent sample discs. The powdered sample of each plant specimen was loaded in FTIR spectroscope (Shimadzu), with a Scan range from 400 to $4000 \mathrm{~cm}^{-1}$ with a resolution of $4 \mathrm{~cm}^{-1}$.

\section{RESULTS AND DISCUSSION}

In the present investigation, spectroscopic characterization was done for the leaf extracts of five plants, Clitoria ternatea, Calotropis gigantea, Mentha arvensis, Aegle marmelos and Catharanthus roseus in three solvents methanol, ethanol and chloroform. The preliminary qualitative investigation of the leaves extract reveals the existence of ten phytochemicals such as carbohydrates, flavonoids, alkaloids, glycosides, saponin, steroids, terpenoids, quinone, tannins and phenols. The spectroscopic interpretation supports the presence of these phytochemicals by the characteristic peak values observed in the Visible and Ultraviolet region. The FTIR spectrum reveals the presence of functional groups such as alcohol, carboxylic acids, aromatic compounds, aldehydes and phenols. Proper investigation of medicinal plants chemical composition and their activity is very important to promote the development of therapeutic compounds.

\section{Phytochemical Screening}

Medicinal plants are important resources of functional therapeutic components for the development of new pharmaceutical products. This current study tends to analyse the phytochemical content in methanol, ethanol and chloroform extract of all the five selected plants. The experimental phytochemical analysis revealed the occurrence of ten phytochemical compounds in these plants such as flavonoids, carbohydrates, glycoside, steroids, alkaloids, saponins, tannin, terpenoids, quinones and phenols. These bioactive agents may contribute to the medicinal efficacy of the plant. The results of phytochemical screening of leaf extracts of selected five plants are depicted in (Table-1).

Table- 1: Result of Qualitative Phytochemical Screening of Leaf Extracts of Five Selected Plants

\begin{tabular}{c|c|c|c|c|c|c|c|c|c|c|c|c|c|c|c|c|c}
\hline & & \multicolumn{3}{|c|}{$\begin{array}{c}\text { Clitoria } \\
\text { S. Nornatea }\end{array}$} & \multicolumn{2}{|c|}{$\begin{array}{c}\text { Calotropis } \\
\text { gigantea }\end{array}$} & \multicolumn{3}{|c}{$\begin{array}{c}\text { Mentha } \\
\text { arvenesis }\end{array}$} & \multicolumn{3}{c|}{$\begin{array}{c}\text { Aegle } \\
\text { marmelos }\end{array}$} & \multicolumn{2}{c}{$\begin{array}{c}\text { Catharanthus } \\
\text { roseus }\end{array}$} \\
\hline & & $\mathrm{M}$ & $\mathrm{E}$ & $\mathrm{C}$ & $\mathrm{M}$ & $\mathrm{E}$ & $\mathrm{C}$ & $\mathrm{M}$ & $\mathrm{E}$ & $\mathrm{C}$ & $\mathrm{M}$ & $\mathrm{E}$ & $\mathrm{C}$ & $\mathrm{M}$ & $\mathrm{E}$ & $\mathrm{C}$ \\
\hline 1 & Alkaloid & + & + & + & + & + & + & + & + & - & + & + & + & + & + & + \\
\hline 2 & Flavonoid & + & + & + & + & + & + & + & + & + & + & + & + & + & + & + \\
\hline 3 & Tannins & + & + & - & + & + & + & + & + & + & + & + & + & + & + & + \\
\hline 4 & Carbohydrates & + & + & + & + & + & + & + & + & - & + & + & + & + & - & - \\
\hline 5 & Terpenoids & + & + & - & + & + & + & + & + & + & - & + & + & + & + & + \\
\hline 6 & Steroids & - & - & + & + & + & + & + & + & + & - & + & - & + & + & - \\
\hline 7 & Quinones & + & - & - & - & + & - & - & - & - & - & - & - & + & + & + \\
\hline 8 & Saponins & + & + & + & + & + & + & + & + & + & + & + & + & + & + & - \\
\hline 9 & Glycosides & + & + & + & - & + & + & + & + & + & + & - & + & + & + & + \\
\hline 10 & Phenols & + & + & - & + & + & - & - & + & + & + & + & + & + & + & + \\
\hline
\end{tabular}

*M=methanol, $\mathrm{E}=$ ethanol, $\mathrm{C}=$ chloroform, $(+)$ indicates the presence and $(-)$ indicates the absence of the phytochemical. 
RASĀYAN J. Chem.

Vol. 14 | No. 2 |1423-1434| April - June | 2021

In recent times, phytochemicals have attained attention due to their ethnomedicinal properties and hence applied in the prevention and cure of various ailments. Alkaloids possess antifungal, antimicrobial, and anti-inflammatory properties and also act as anti-hypertensive agents. ${ }^{21}$ Pharmacological properties such as antiviral, anti-inflammatory, expectorant, vein tonic, hypoglycaemic, wound healing, spasmolytic and antimicrobial are shown by saponins extracted from plants. ${ }^{22}$ Terpenoids show various essential pharmacological properties such as antimalarial, anti-inflammatory, antiviral, anticancer, cholesterol synthesis inhibition and antibacterial properties. ${ }^{24}$ Flavonoids possess antimicrobial, anti-inflammatory, antioxidant, vascular properties. ${ }^{23}$ and other medicinal properties like anti-allergic, antispasmodic, antiviral, and diuretic effect. ${ }^{25}$ Phenolic compounds act as antioxidants and are responsible for a varying range of medicinal values such as anticancer, diabetes anti-inflammatory, ${ }^{26,27}$ antiviral and cytotoxic activity. ${ }^{28}$ Tannins possess antibacterial, antiviral, and anti-tumour properties. ${ }^{29}$ It is reported that to reduce stress, cholesterol levels steroids are found to be beneficial. It is also used for activating the immune system, enhancing learning and memory and treating tumour cells. ${ }^{30-32}$ Glycosides are found beneficial in lowering blood pressure as per earlier reports given. ${ }^{33}$ Carbohydrate is enormously used in haematological and cardiovascular treatments, in inflammatory and anti-thrombotic remedies to heal wounds. ${ }^{34}$ it has been seen that quinone-containing compounds are approved clinically in recent years, used in drugs for cancer clinical trials. Quinones have antioxidant potentials and hence are generally used as vitamins for preventing and curing various ailments and in improving health conditions. It is also used in osteoporosis and cardiovascular diseases. It has been reported that quinones have toxicological effects as photoproducts from air pollutants. ${ }^{35}$

\section{The Ultraviolet-Visible Spectroscopy}

In recent years for the quantitative and qualitative analysis of biological and pharmaceutical materials, the Spectroscopic technique has been extensively used as a powerful and analytical tool. The plant extracts obtained as above were scanned using a UV-VIS spectrophotometer in the wavelength range of 200$700 \mathrm{~nm}$ and the characteristic peaks were detected and recorded as illustrated in (Table-2).

Table-2: UV-VIS Data for Leaf Extracts of Selected Five Plants

\begin{tabular}{|c|c|c|c|c|c|c|c|c|c|c|}
\hline \multirow[t]{2}{*}{ Solvent } & \multicolumn{2}{|c|}{$\begin{array}{l}\text { Clitoria } \\
\text { ternatea }\end{array}$} & \multicolumn{2}{|c|}{ Calotropis gigantea } & \multicolumn{2}{|c|}{ Mentha arvenesis } & \multicolumn{2}{|c|}{ Aegle marmelos } & \multicolumn{2}{|c|}{$\begin{array}{c}\text { Catharanthus } \\
\text { roseus }\end{array}$} \\
\hline & $\begin{array}{c}\lambda \\
\max (\mathrm{nm})\end{array}$ & Abs & $\begin{array}{c}\lambda \\
\max (\mathrm{nm})\end{array}$ & Abs & $\begin{array}{c}\lambda \\
\max (\mathrm{nm})\end{array}$ & Abs & $\begin{array}{c}\lambda \\
\max (\mathrm{nm})\end{array}$ & Abs & $\begin{array}{c}\lambda \\
\max (\mathrm{nm})\end{array}$ & Abs \\
\hline Methanol & $\begin{array}{l}666 \\
608 \\
536 \\
506\end{array}$ & $\begin{array}{l}2.37 \\
0.83 \\
1.03 \\
1.15\end{array}$ & $\begin{array}{l}672 \\
610 \\
536\end{array}$ & $\begin{array}{c}3.0 \\
1.51 \\
1.18\end{array}$ & $\begin{array}{l}664 \\
608 \\
536 \\
506\end{array}$ & $\begin{array}{l}2.29 \\
0.54 \\
0.60 \\
0.66\end{array}$ & $\begin{array}{l}664 \\
616 \\
416\end{array}$ & $\begin{array}{l}1.84 \\
0.47 \\
2.69\end{array}$ & $\begin{array}{l}670 \\
660 \\
614 \\
538\end{array}$ & $\begin{array}{l}3.0 \\
2.97 \\
1.43 \\
0.70\end{array}$ \\
\hline Ethanol & $\begin{array}{l}664 \\
606 \\
534 \\
436 \\
504 \\
\end{array}$ & $\begin{array}{l}2.69 \\
0.64 \\
0.79 \\
3.00 \\
0.92\end{array}$ & $\begin{array}{l}656 \\
614 \\
538 \\
380 \\
336 \\
\end{array}$ & $\begin{array}{c}3.0 \\
1.87 \\
1.01 \\
3.0 \\
2.77 \\
\end{array}$ & $\begin{array}{l}664 \\
606 \\
422 \\
506 \\
534 \\
\end{array}$ & $\begin{array}{l}2.38 \\
0.54 \\
3.00 \\
0.74 \\
0.66\end{array}$ & $\begin{array}{l}664 \\
618 \\
434 \\
416\end{array}$ & $\begin{array}{l}1.84 \\
0.46 \\
2.65 \\
2.65\end{array}$ & $\begin{array}{l}662 \\
614 \\
536\end{array}$ & $\begin{array}{l}0.56 \\
0.52 \\
1.16\end{array}$ \\
\hline Chloroform & $\begin{array}{l}668 \\
610 \\
538\end{array}$ & $\begin{array}{l}2.83 \\
0.82 \\
1.29\end{array}$ & $\begin{array}{l}364 \\
392 \\
608\end{array}$ & $\begin{array}{l}2.50 \\
1.21 \\
0.04\end{array}$ & $\begin{array}{l}668 \\
610 \\
538 \\
506\end{array}$ & $\begin{array}{l}2.71 \\
0.77 \\
1.04 \\
1.15\end{array}$ & $\begin{array}{l}668 \\
610 \\
538 \\
414 \\
378\end{array}$ & $\begin{array}{l}1.14 \\
0.22 \\
0.33 \\
3.00 \\
2.17\end{array}$ & $\begin{array}{l}664 \\
610 \\
538\end{array}$ & $\begin{array}{l}2.99 \\
1.05 \\
1.27\end{array}$ \\
\hline
\end{tabular}

The UV-VIS profile of methanol extract of Clitoria ternatea peaks was observed at $666,608,536$ and $506 \mathrm{~nm}$ with the absorption value of 2.37, $0.83,1.03$ and 1.15 respectively. The ethanol extract of Clitoria ternatea leaves showed peaks at $664,606,534,436$ and $504 \mathrm{~nm}$ with the absorption of 2.69, 0.64, 0.79, 3.00 and 0.92 respectively. Chloroform extract of Clitoria ternatea leaves indicated the peaks at 668,610 and $538 \mathrm{~nm}$ showing the absorption values of $2.83,0.82$ and 1.29 respectively. 
RASĀYAN J. Chem.

Vol. 14 | No. 2 |1423-1434| April - June | 2021

The UV-Visible spectra results obtained in the methanolic extract of Calotropis gigantea leaves showed the absorption 3.0, 1.51 and 1.18 at 672,610 and $536 \mathrm{~nm}$. The peaks observed in spectroscopic analysis in the UV-Visible region supports the presence of phytochemicals like flavonoids and alkaloids. The ethanolic extract of leaves showed peaks at $656,614,538,380$ and $336 \mathrm{~nm}$ with the absorption of 3.0, $1.87,1.01,3.01$ and 2.77 respectively. UV-Vis spectrum with absorption bands at $400-550 \mathrm{~nm}$ and $600-$ $700 \mathrm{~nm}$ indicate the occurrence of flavonoids and their derivatives, terpenoids and chlorophyll in the crude extracts. In the current analysis the peak values observed for chloroform extract of Calotropis gigantea leaves are shown at 364, 392 and $608 \mathrm{~nm}$ with the absorption values of 2.50, 1.21 and 0.04 respectively.

The methanol extract of Mentha arvensis showed the peaks UV-VIS peaks at 664, 608, 536 and $506 \mathrm{~nm}$ having absorption values of 2.29,0.54, 0.60 and 0.66 . The ethanolic extract of Mentha arvensis leaves showed peaks at $664,606,422,506$ and $534 \mathrm{~nm}$ with the absorption of 2.38, 0.54, 3.00, 0.742 and 0.66 respectively. For the Chloroform extract of leaves the peaks observed at 668, 610, 538 and $506 \mathrm{~nm}$ and $2.71,0.77,1.04$ and 1.15 absorption values respectively.

The UV-Visible spectrum obtained in the extract made in methanol of Aegle marmelos leaves showed the absorption of 1.84, 0.47 and 2.69 at 664,616 and $416 \mathrm{~nm}$. The ethanolic extract of leaves indicated the wavelength at $664,618,434$ and $416 \mathrm{~nm}$ having an absorption of 1.84, 0.46, 2.65 and 2.60. In chloroform solvent, the extract of Aegle marmelos showed the absorbance of 1.14, 0.22, 0.33, 3.00 and 2.17 at 668 , $610,538,414$ and $378 \mathrm{~nm}$ wavelengths respectively.

UV-Vis spectrum with absorption bands at $670,660,614$ and $538 \mathrm{~nm}$ was observed with the absorption of 3.00, 2.97, 1.43 and 0.70 respectively in the methanol extract of Catharanthus roseus. The ethanol extract shows the absorption of 3.00, 1.29 and 0.68 with a wavelength of 662,614 and $536 \mathrm{~nm}$ respectively. The qualitative UV-Vis spectrum profile in chloroform extract was selected from 200 to 700 $\mathrm{nm}$. The peaks were obtained at 664,610 and $538 \mathrm{~nm}$ which shows the absorption of $2.99,1.05$ and 1.27 respectively.

\section{Fourier Transform Infrared Spectroscopy}

FTIR spectroscopic technique was applied for the identification of functional group present in the phytochemicals of leaves which is determined based on the peak values observed in the infrared region radiation. The FTIR spectrum reveals the existence of characteristic phytochemical components in the extracts of selected plant leaves. The functional groups were differentiated based on their peak ratio in the spectrum.

In the present study, the FTIR spectrum obtained for the leaf extract of Clitoria ternatea shows the existence of an extensive range of functional groups of biologically active components. The FTIR spectral values and functional groups determined were illustrated in (Fig.-1 and Table-3).

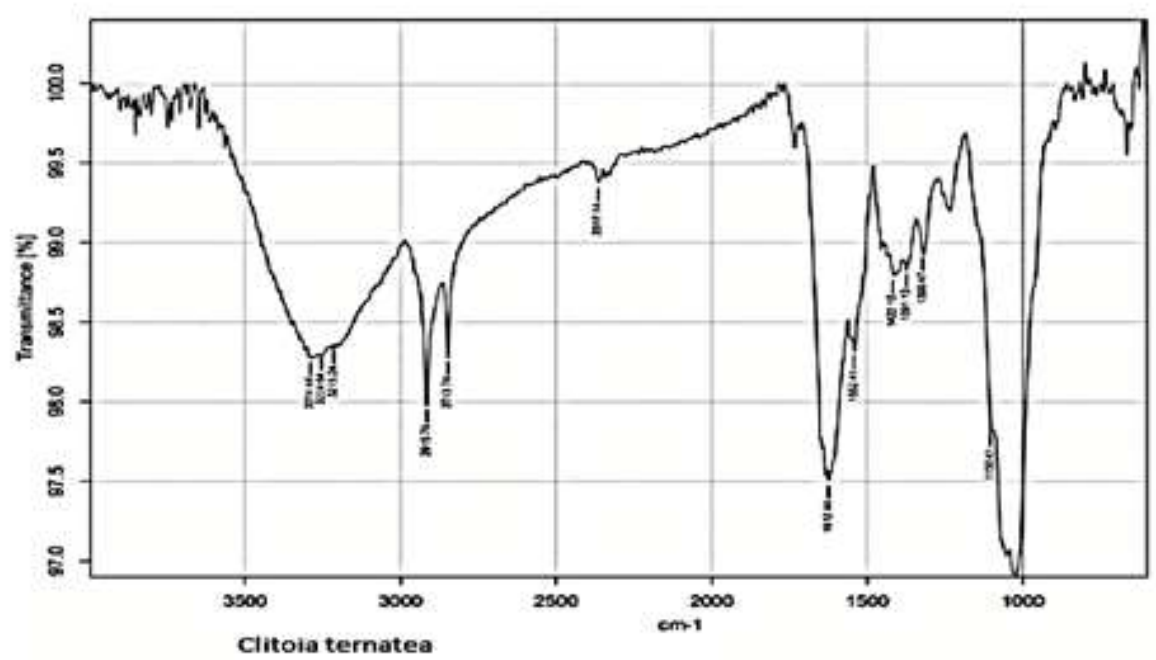

Fig.-1: FTIR Spectrum of Clitoria ternatea 
RASĀYAN J. Chem.

Vol. 14 | No. 2 |1423-1434| April - June | 2021

FTIR spectra analyses confirm the existence of alcohols and phenols having a value of peak at 3314.44 $\mathrm{cm}^{-1}$ which corresponds to $\mathrm{O}-\mathrm{H}$ stretch. The peak at $3224.64 \mathrm{~cm}^{-1}$ represents the $\mathrm{O}-\mathrm{H}$ stretching which shows that carboxylic acids are present. The value of peak at $3215.24 \mathrm{~cm}^{-1}$ attributing to the $\mathrm{N}-\mathrm{H}$ stretch reveals the occurrence of amides. The peak value at $2915.74 \mathrm{~cm}-1$ denoted to the $\mathrm{C}-\mathrm{H}$ stretch reveals the appearance of aliphatic components. The value of the peak at $2713.74 \mathrm{~cm}^{-1}$ indicates aldehydes. The wavelength at $1612.44,1552.41 \mathrm{~cm}^{-1}$ and $1422.10 \mathrm{~cm}^{-1}$ allocated to the $\mathrm{C}-\mathrm{H}$ stretch and $\mathrm{C}-\mathrm{C}=\mathrm{C}$ Symmetric Stretch show that some aromatic ring compounds are present. The peaks observed at $1319.13 \mathrm{~cm}^{-1}$ correspond to the $\mathrm{C}-\mathrm{H}$ stretch represents carboxylic acids, esters, ethers. The value of the peak at 1300.4 $\mathrm{cm}^{-1}$ confirms the aromatic amine.

Table-3: FTIR Data for Extract of Clitoria ternatea Leaves

\begin{tabular}{c|c|c}
\hline $\begin{array}{c}\text { Peak Value } \\
\text { Wavenumber }\left(\mathrm{cm}^{-1}\right)\end{array}$ & Functional Groups and Class & Assignment and Remarks \\
\hline 3314.44 & Phenols and Alcohols & O-H Stretch \\
\hline 3224.64 & Carboxylic acids & O-H stretch \\
\hline 3215.24 & Amides & C-H stretch \\
\hline 2915.74 & $\mathrm{CH}_{2}$ in aliphatic compounds & H-C=O stretch \\
\hline 2713.74 & Aldehydes & C-C stretch (in-ring) \\
\hline 1612.44 & Aromatics & C-C=C Symmetric Stretch \\
\hline 1552.41 & Aromatic Rings & C=C stretch \\
\hline 1422.10 & Aromatic & C-O stretch \\
\hline 1319.13 & Carboxylic acids, esters, ethers & C-N stretch \\
\hline 1300.4 & Aromatic amines &
\end{tabular}

In the present study, the biochemical content of Calotropis gigantea was determined using an FTIR spectrophotometer and monitored different functional groups. (Fig.-2) indicates the respective FT-IR spectra. The FT-IR peak values observed, and functional groups determined were given in (Table-4). The FT-IR gave a peak at 3214.24 and $1615 \mathrm{~cm}^{-1}$ which indicated the presence of $\mathrm{N}-\mathrm{H}$ stretch due to amines. The observed peak at $2955.10 \mathrm{~cm}-1$ infers the $\mathrm{C}-\mathrm{H}$ stretch present due to alkanes. The value of peak at $1513.52 \mathrm{~cm}^{-1}$ indicates $\mathrm{N}-\mathrm{O}$ Stretch which shows the presence of nitro compounds. The existence of $\mathrm{C}=\mathrm{O}$ stretching due to alkanes and aldehydes is confirmed by the peak obtained at $2850.58 \mathrm{~cm}^{-1}$. The peak of $1101.52 \mathrm{~cm}^{-1}$ is specified to C-N stretching of aliphatic amines and the wavelength value of $1050.25 \mathrm{~cm}^{-1}$ shows $\mathrm{C}-\mathrm{O}$ stretch due to alcohols.

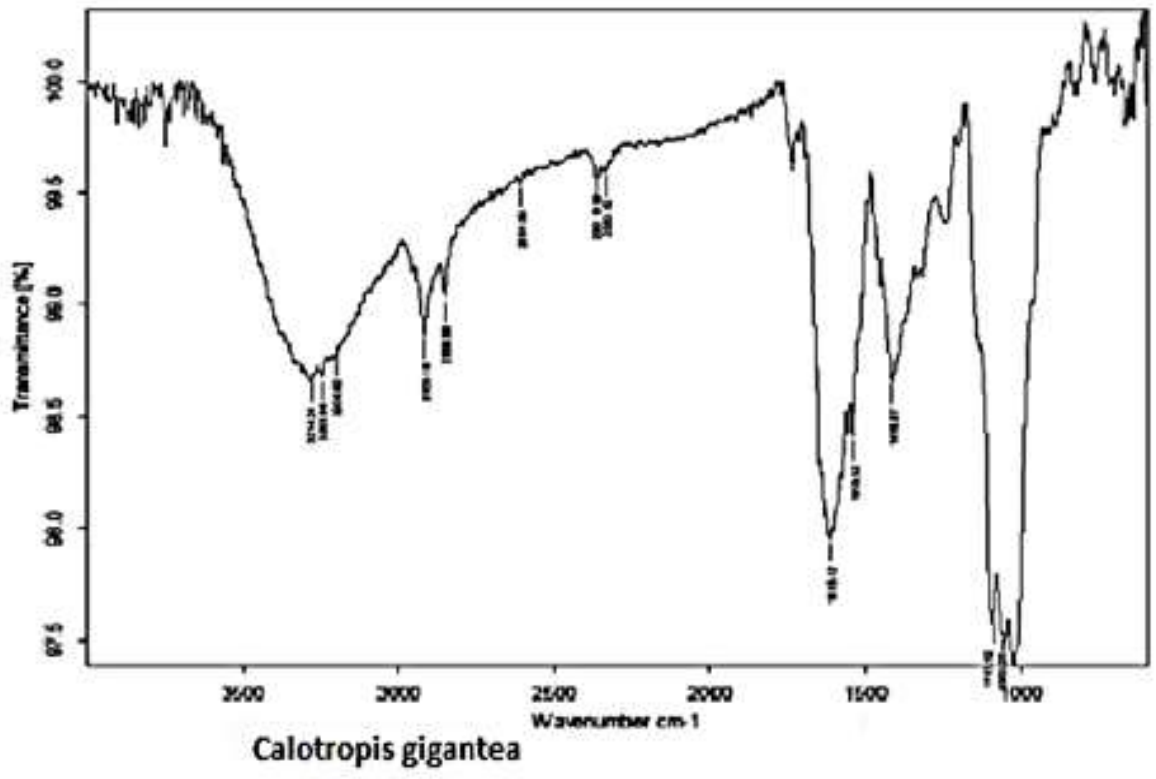

Fig.-2: FTIR Spectrum of Calotropis gigantea 
RASĀYAN J. Chem.

Vol. 14 | No. 2 |1423-1434| April - June | 2021

Table- 4: FTIR Data for Different Extracts of Calotropis gigantea Leaves

\begin{tabular}{c|c|c}
\hline $\begin{array}{c}\text { Peak Value } \\
\text { Wavenumber }\left(\mathrm{cm}^{-1}\right)\end{array}$ & $\begin{array}{c}\text { Functional Groups and } \\
\text { Class }\end{array}$ & Assignment and Remarks \\
\hline 3214.24 & Amines & N-H stretch \\
\hline 2955.10 & Alkanes & C-H stretch \\
\hline 2850.58 & Alkanes, Aldehydes & sp3 C-H stretch, C=O \\
\hline 1615.12 & $1^{\circ}$ amines & N-H bend \\
\hline 1513.52 & Nitro Compounds & N-O asymmetric stretch \\
\hline 1101.52 & Aliphatic Amines & C-N stretch \\
\hline 1050.25 & Alcohols & C-O stretch \\
\hline
\end{tabular}

The spectrum of FTIR of leaf extract of Mentha arvensis determines the functional group of the active constituents existing and is determined based on the peak value in the infrared radiation region. The FTIR spectrum of the Mentha arvensis plant extract in the form of a $\mathrm{KBr}$ pallet is shown in (Fig.-3 and Table5). The absorption at $2916.37 \mathrm{~cm}^{-1}$ is because of the $\mathrm{C}-\mathrm{H}$ stretch corresponding to the absorption of methylene in aliphatic compounds that are present in the extract. The band at $2850.79 \mathrm{~cm}^{-1}$ and 2704.2 $\mathrm{cm}^{-1}$ is due to the symmetric stretching of saturated C-H (sp3) carbon in aldehyde. The wavelength at $2360.87 \mathrm{~cm}-1$ represents phosphine. The band at $1734.01 \mathrm{~cm}^{-1}$ is due to $\mathrm{C}=\mathrm{O}$ stretching associated with the saturated aliphatic compound and aldehydes. The absorption band at $1440.18 \mathrm{~cm}^{-1}$ was assigned to P$\mathrm{C}-\mathrm{H}$ Bend represents the Organo-phosphorus compound and the band at 1404.18 shows aromatics. The band at $1261.45 \mathrm{~cm}^{-1}$ can be assigned to the $\mathrm{C}-\mathrm{O}$ stretch represents ethers, carboxylic acids, alcohols, esters. The band observed at $1166.93 \mathrm{~cm}-1$ represent the aliphatic amines. Due to the C-O stretch that exists in the extract, the absorption is observed at $1035.77 \mathrm{~cm}^{-1}$ and reveals primary alcohols. The band at $921.97 \mathrm{~cm}^{-1}$ represents carboxylic acid.

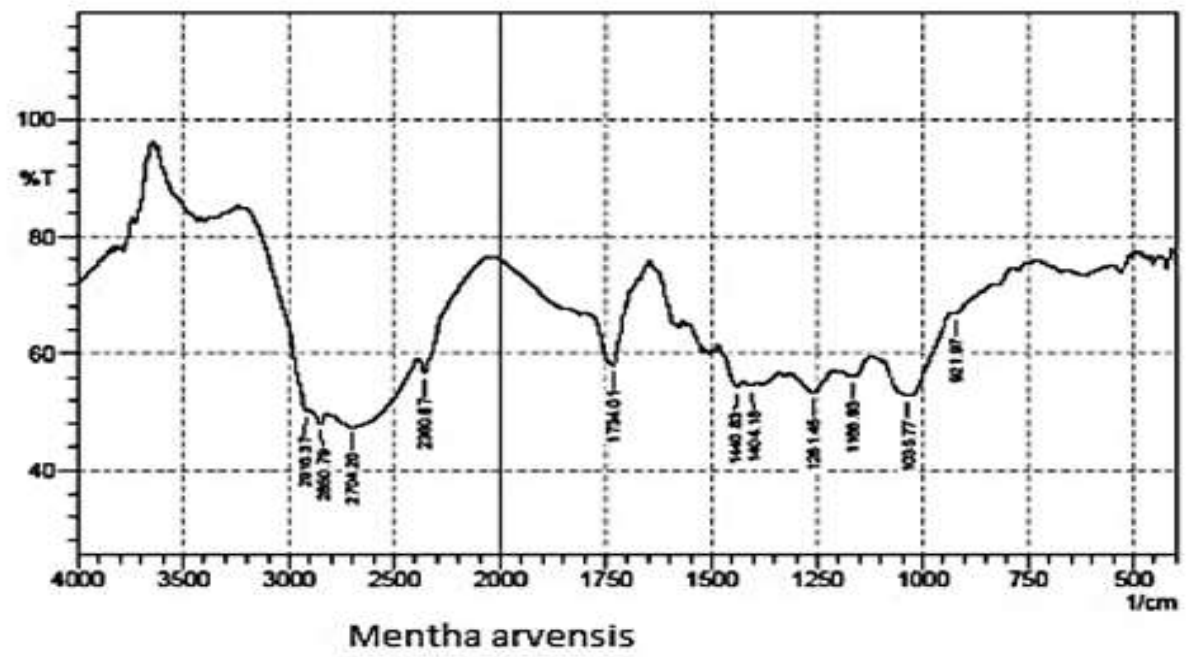

Fig.-3: FTIR Spectrum of Mentha arvensis

Table- 5: FTIR Data for Plant Extract of Mentha arvensis Leaves

\begin{tabular}{c|c|c}
\hline $\begin{array}{c}\text { Peak Value } \\
\text { Wavenumber }\left(\mathrm{cm}^{-1}\right)\end{array}$ & Functional Groups and Class & $\begin{array}{c}\text { Assignment and } \\
\text { Remarks }\end{array}$ \\
\hline 2916.37 & $\mathrm{CH}$ in aliphatic compounds & C-H stretch \\
\hline 2850.79 & C-H in aldehyde & $\mathrm{SP}^{3} \mathrm{C}-\mathrm{H}$ stretch \\
\hline 2704.2 & Aldehyde & $\mathrm{H}-\mathrm{C}=\mathrm{O}: \mathrm{C}-\mathrm{H}$ stretch \\
\hline 2360.87 & Misc. Phosphine & C-H stretch \\
\hline 1734.01 & $\begin{array}{c}\text { Aldehydes, Saturated } \\
\text { Aliphatic }\end{array}$ & $\mathrm{C}=\mathrm{O}$ stretch \\
\hline 1440.83 & Organophosphorus & P-C-H Bend \\
\hline
\end{tabular}


RASĀYAN J. Chem.

Vol. 14 | No. 2 |1423-1434| April - June | 2021

\begin{tabular}{c|c|c}
\hline & Compound & \\
\hline 1404.18 & Aromatics & C-C stretch \\
\hline 1261.45 & $\begin{array}{c}\text { Presence of Alcohols, } \\
\text { Carboxylic acids, Esters, } \\
\text { Ethers }\end{array}$ & C-O stretch \\
\hline 1166.93 & Aliphatic amines & C-N stretch \\
\hline 1035.77 & $\begin{array}{c}\text { C=CH2-OH in Primary } \\
\text { Alcohol }\end{array}$ & C-O stretch \\
\hline 921.97 & Carboxylic acids & O-H bend \\
\hline
\end{tabular}

Structural details of various chemical components of the leaf extract of Aegle marmelos are revealed by the results of FTIR investigation which is differentiated by their peaks. Interpretation of absorption spectrum obtained from FTIR spectra with their wavenumbers and absorption bands are given in (Fig.-4 and Table-6).

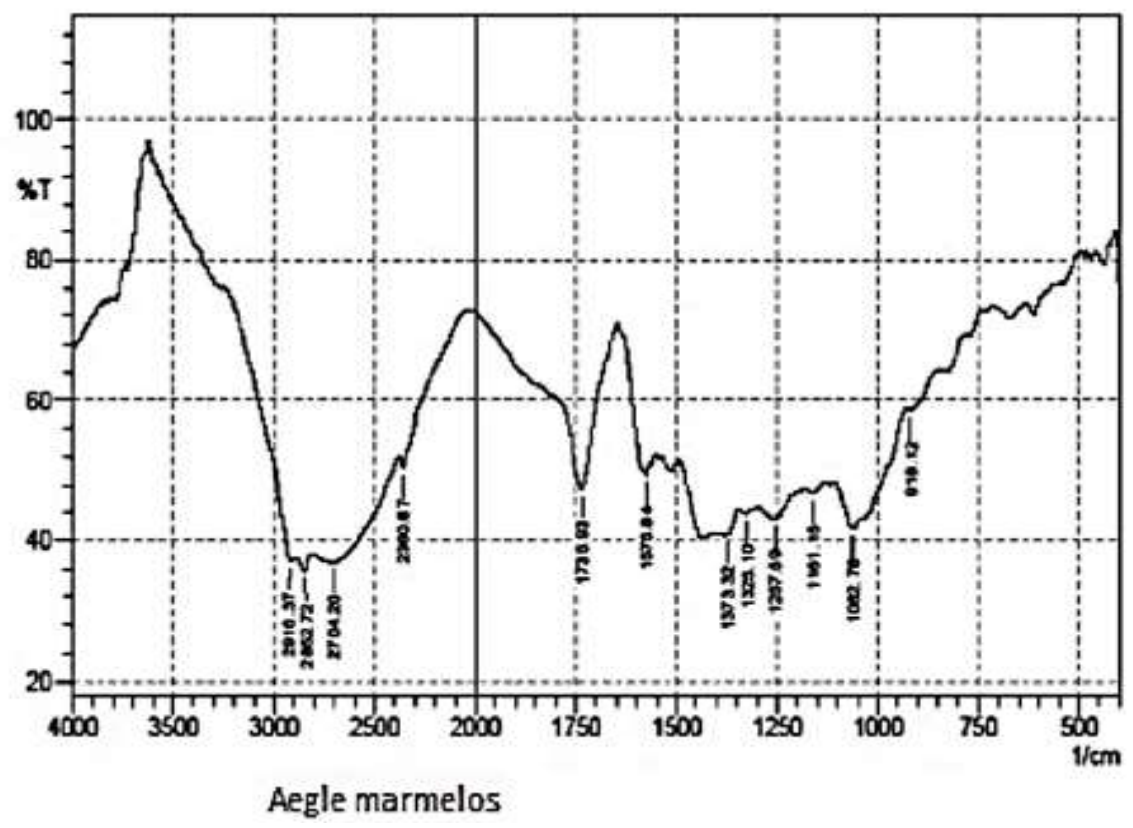

Fig.-4: FTIR Spectrum of Aegle marmelos

Table- 6: FTIR Data for Extract of Aegle marmelos Leaves

\begin{tabular}{c|c|c}
\hline $\begin{array}{c}\text { Peak Value } \\
\text { Wavenumber }\left(\mathrm{cm}^{-1}\right)\end{array}$ & Functional Groups and Class & Assignment and Remarks \\
\hline 2916.37 & $\mathrm{CH}_{2}$ in aliphatic compounds & C-H stretch \\
\hline 2852.72 & C-H in aldehyde & SP ${ }^{3}$-H stretch \\
\hline 2704.2 & Aldehydes & $\mathrm{H}-\mathrm{C}=\mathrm{O}: \mathrm{C}-\mathrm{H}$ stretch \\
\hline 2360.87 & Misc. Phosphine & \\
\hline 1735.95 & Esters & R-C(O)-O-R C=O stretch \\
\hline 1575.84 & Primary amine & N-H Bend \\
\hline 1373.32 & Alkanes, Alkyls & C-H $-\mathrm{H}$ bend \\
\hline 1325.1 & Aromatic amine & O=C-O-C stretch \\
\hline 1257.59 & Aromatic compound & C-N stretch \\
\hline 1161.15 & Aliphatic amines & C-O stretch \\
\hline 1062.78 & Alcohols, ethers & O-H bend
\end{tabular}


RASĀYAN J. Chem.

Vol. 14 | No. 2 |1423-1434| April - June | 2021

The peaks observed at $2916.37,2704.2 \mathrm{~cm}^{-1}$ and $2852.72 \mathrm{~cm}^{-1}$ correspond to the $\mathrm{C}-\mathrm{H}$ stretch represents the absorption of methylene in aliphatic compounds and aldehydes. The peak intensities at 2360.87, 1735.95, and $1575.84 \mathrm{~cm}^{-1}$ spectra show the presence of phosphine, esters and primary amines respectively. The peak at $1373.32 \mathrm{~cm}-1$ reveals the presence of alkane and alkyls. The bands at $1325.1 \mathrm{~cm}-1$ correspond to $\mathrm{C}-\mathrm{N}$ stretch represents aromatic amine. The peak at $1257.59 \mathrm{~cm}^{-1}$ is mainly generated by aromatic compounds. Absorption bands observed at $1161.15 \mathrm{~cm}^{-1}$ indicate primary amine. Alcohols, Cyclic ethers and carboxylic acids were detected at 1062.78 and $918.12 \mathrm{~cm}^{-1}$ respectively.

The FT-IR analysis of Catharanthus roseus plant leaves is depicted in (Fig.-5). The phytochemical involvement of various functional groups in the plant extract is monitored and the resultant functional groups are listed in (Table-7).

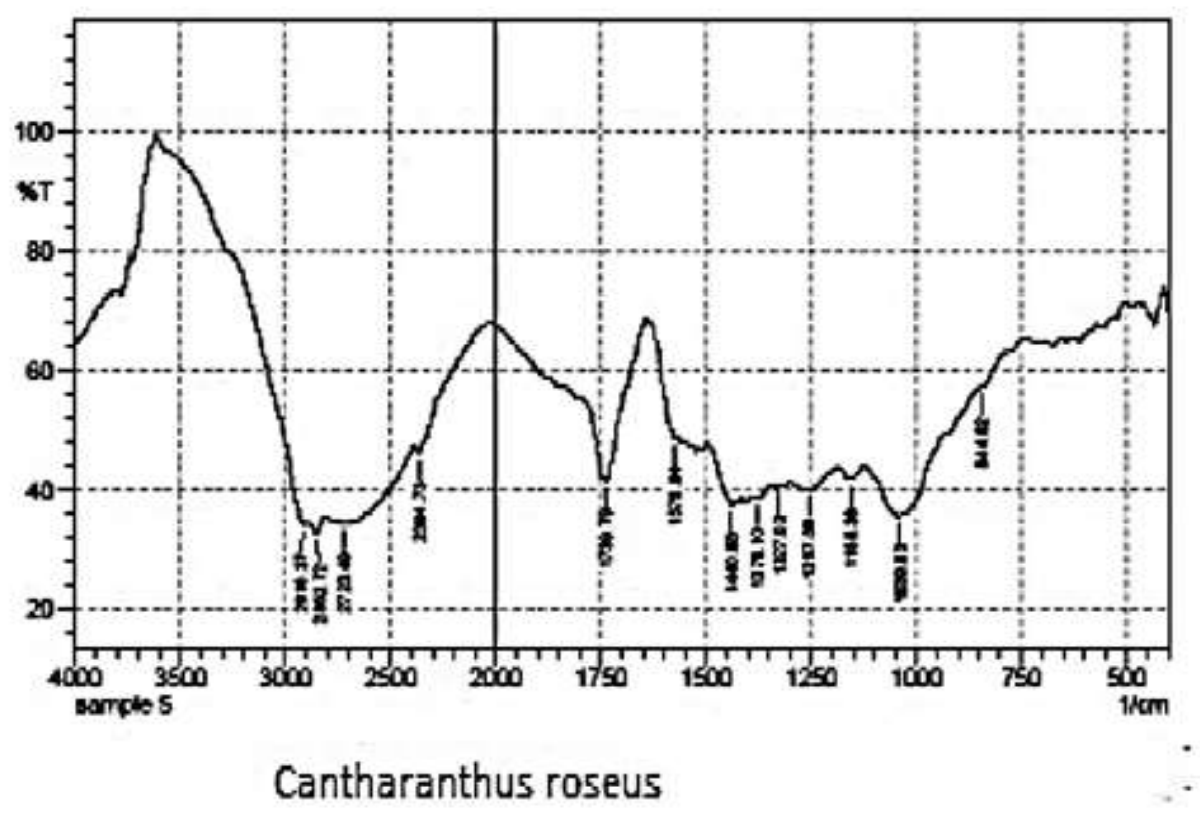

Fig.-5: FTIR Spectrum of Catharanthus roseus

Table-7: FTIR Data for Extract of Catharanthus roseus Leaves

\begin{tabular}{c|c|c}
\hline $\begin{array}{c}\text { Peak Value } \\
\text { Wavenumber }\left(\mathrm{cm}^{-1}\right)\end{array}$ & Functional Groups and Class & Assignment and Remarks \\
\hline 2916.37 & $\mathrm{CH}_{2}$ in Aliphatic compounds & C-H stretch \\
\hline 2852.72 & C-H in Aldehyde & SP ${ }^{3}$-H stretch \\
\hline 2723.49 & Aldehyde & H-C C-H stretch \\
\hline 2364.73 & Misc. Phosphine & C=O Stretch \\
\hline 1739.79 & Esters & P-H Bend \\
\hline 1575.84 & Primary amine & CH3 C-H bend \\
\hline 1440.83 & Organophosphorus & C-N stretch \\
\hline 1379.1 & compound & C-O stretch \\
\hline 1327.03 & Alkanes, Alkyls & C-O stretch \\
\hline 1257.59 & Aromatic Amines & C-O stretch \\
\hline 1155.36 & Esters, Ethers & C-Cl stretch \\
\hline 1039.63 & Alcohols & C-H stretch \\
\hline 844.82 & Primary Alcohols & C-N stretch \\
\hline 2976 & Alkyl halides & C-H stretch \\
\hline 1045 & Alkanes &
\end{tabular}


RASĀYAN J. Chem.

Vol. 14 | No. 2 |1423-1434| April - June | 2021

The peak at 2916.37, $2852.72 \mathrm{~cm}^{-1}$ and $2723.49 \mathrm{~cm}^{-1}$ represent the C-H stretching indicates the absorption of methylene in aliphatic compounds and aldehydes respectively. The peak at $2364.73 \mathrm{~cm}^{-1}$ shows Misc. Phosphine and the value of peak at $1440.83 \mathrm{~cm}^{-1}$ were attributed to the P-C-H bend of the Organophosphorus compound. The predominant peak at $1739.79 \mathrm{~cm}^{-1}$ and $1257.59 \mathrm{~cm}^{-1}$ was attributed to the $\mathrm{C}=\mathrm{O}$ Stretch of esters and ethers. The peak at $1155.36 \mathrm{~cm}^{-1}$ and $1039.63 \mathrm{~cm}^{-1}$ are attributed to the $\mathrm{C}-\mathrm{O}$ stretching due to the alcohol group. The peak of $1045.0 \mathrm{~cm}^{-1}$ is specified to C-N stretching of aliphatic amines and the peak of $1327.03 \mathrm{~cm}^{-1}$ is specified to aromatic amines. The peak at 882.0 is specified to the C-H stretch of aromatics. The peak value at $2976.0 \mathrm{~cm}^{-1}$ and $1379.1 \mathrm{~cm}^{-1}$ are specified to $\mathrm{C}-\mathrm{H}$ stretch vibration of Alkanes and Alkyls and the peak at 1575.84 is due to a primary amine. The value of the peak at $1376.43 \mathrm{~cm}^{-1}$ reveals alkyl halides. The analysis by FTIR confirmed the occurrence of phytochemicals belongs to the functional groups such as alkyl halides, aliphatic and aromatic amines, alcohols, esters, ethers, alkanes, nitro group, aromatic hydrocarbons, Carbonyl group, and phenols in Catharanthus roseus.

\section{CONCLUSION}

The present study reveals the therapeutic potency of leaves of five selected noteworthy plants. From the results of qualitative analysis of Phytochemical compounds, it is concluded that all the five selected plant leaves consist of phytochemicals such as phenols, saponins, glycosides,flavonoids, alkaloids, carbohydrates, tannins, and terpenoids in the most prominent amount while steroids and quinone are in less amount. Based on previous investigation reports, the phytochemicals found to be present in the selected plant leaves indicates their pharmacological potential as a natural antioxidant, anticancer, antiinflammatory, antimicrobial, anti-diarrhoeic and anti-haemorrhagic agents. Results showed that the methanol extracts of the leaves of the plant consist of a good source of phytochemicals as compared to the chloroform and ethanol extract. Characterization of leaf extracts by UV-VIS and FTIR spectroscopy confirms the presence of various functional groups such as alcohol, carboxylic acids, aromatic compounds, aldehydes, amines, ethers, esters and phenols present which will be helpful to elucidate the structure and composition of phytochemicals. From the present study, it can be concluded that selected five plant leaves are the excellent authentic source of ten significant phytochemicals which could be used to produce novel useful drugs, herbal formulation, and alternative medicines for various ailments.

\section{ACKNOWLEDGEMENT}

The authors are grateful to SSPA, Pt. R.S.U Raipur for providing facilities for FTIR analyses. We are also thankful to BIT, Durg for providing lab facilities to conduct this research study.

\section{REFERENCES}

1. P.T.Motsumi, T.Qwebani-Ogunleye, I.P.Ejidike, F.M.Mtunzi and Z. Nate, Rasayan Journal of Chemistry, 13(1), 423(2020), DOI:10.31788/1315594

2. P.Tiwari, B.Kumar, M. Kaur, G. Kaur, H.Kaur, Internationale Pharmaceutica Sciencia, 1(1), 98(2011).

3. D.koche, R. Shirsat, M.kawale, Hislopia Journal, 9(1/2), 976(2016).

4. K.S. Banu, Dr L.Cathrine, International Journal of Advanced Research in Chemical Science, 2(4), 25(2015).

1. M. Saxena, J. Saxena, R. Nema, D.Singh and A. Gupta, Journal of Pharmacognosy and Phytochemistry, 1(6), 2278(2013).

2. D.W. Nyamai, W.Arika, P.E. Ogola, E.N.M.Njagi, M.P.Ngugi, Journal of Pharmacognosy and Phytochemistry, 4(1), 2321(2016).

3. Sarvesh Kumar1, Vijay Jyoti Kumar and Ranjit Singh, Rasayan Journal of Chemistry, 13(3), 1637(2020), DOI: 10.31788/RJC.1345818

4. Ajay Singh and Mansi Gupta, Rasayan Journal of Chemistry, 11(1), 228(2018) DOI: $10.7324 /$ RJC.1111999

5. Archna Kare, Hanwant Kumar and Bhaswati Chowdhary, International Journal of Current Microbiology and Applied Sciences, 7(9), 672(2018), DOI:10.20546/ijcmas.2018.709.079 
RASĀYAN J. Chem.

Vol. 14 | No. 2 |1423-1434| April - June | 2021

6. C.H.N.Durga Maha Lakshmi, Indo American Journal of Pharmaceutical Research, 4(09), 2231 (2014).

7. P. Chandrawat and R.A. Sharma, Journal of Pharmacognosy and Phytochemistry, 7(5), 1592(2018)

8. Aarti. C, International Journal of Recent Scientific Research, 5(4), 716(2014).

9. N. Sharma, D. Jocob, Journal of Ethnopharmacology, 75, 5(2001).

10. Khudhair A. M. Abed AL Ani, Journal of Chemical and Pharmaceutical Research, 8(7), 818(2016)

11. R. Purena, R. Bhatt, Asian Journal of Plant Science and Research, 8(3), 1(2018).

12. M .A. Mir, A. Kumar, A. Goel, Journal of Chemical and Pharmaceutical Research, 10(10), 22(2018).

13. N.Rani, S.Sharma and M. Sharma, Indian Journal of Science and Technology, 9(31), (2016), DOI: $10.17485 / \mathrm{ijst} / 2016 / \mathrm{v} 9 \mathrm{i} 31 / 94875$

14. R. A. Kumar and M. Ramaswamy, International Journal of Current Microbiology and Applied Sciences, 3(1), 395(2014).

15. R. Dhivya and K. Manimegalai, World Journal of Pharmacy and Pharmaceutical Sciences, 5(10), 1510 (2016).

16. N. Jaradat, F.Hussen and A.A. Ali, Journal of Materials and Environmental Science, 6(6), 1771(2015)

17. D.E Okwu, M.E. Okwu, Journal of Sustainable Development Agricultural Environment, 6, 140(2004).

18. R. Onike, Phytochemical-Screening-Tests-And-MedicinalValues-Of-Plants-Active-Properties, http://searchwarp.com/swa599816(2010)

19. S. B. Mahato and S. Sen, Phytochemistry, 44, 236(1997).

20. J. B. Harborne and C. A. Willians, Phytochemistry, 55(6), 481(2000), DOI:10.1016/S00319422(00)00235-1

21. M. M. Cowan, Clinical Microbiology Reviews, 12, 564(1999).

22. R. U. Hamzah, E. C. Egwim, A. Y. Kabiru, M. B. Muazu, Oxidants and Antioxidants in Medical Science, 2(3), 217 (2013), DOI: 10.5455/oams.090513.or.043

23. V. Nagavani, Y. Madhavi, D. B. Rao, P. K. Rao, T. R. Rao, Electronic Journal of Environmental, Agricultural and Food Chemistry, 9(9), 1471(2010).

24. S. C. Chhabra, F.C. Viso, E. N. Mshiu, Journal of Ethnopharmacology, 11(2),157(1984), DOI: $10.1016 / 0378-8741(84) 90037-0$

25. A. Scalbert, Phytochemistry, 30, 3875 (1991)

26. A. Grandhi, Journal of Ethnopharmacology, 3, 131(1994)

27. S. Panda, A. Kar, Indian Journal of Physiology and Pharmacology, 41,424(1997).

28. S. Veena, S. Sadhana, Pracheta, P. Ritu, International Journal of PharmTech Research, 3,187(2011)

29. A.A. Nyarko, M.E. Addy, Phytotherapy Research, 4(1), 25(1990).

30. M. Kilcoyne and L. Joshi, Cardiovascular and Hematological Agents in Medicinal Chemistry, 5(3), 186 (2007), DOI: 10.2174/187152507781058663

31. Nahed El-Najjar, Hala Gali-Muhtasib, Raimo A, Ketola, P. Vuorela, A. Urtti, H. Vuorela, Phytochemistry Reviews, 10, 353(2011).

[RJC-6281/2020] 